\title{
Bioavailability of iron multi-amino acid chelate preparation in mice and human duodenal HuTu 80 cells
}

\author{
Naroa Kajarabille†, Catriona Brown, Anamaria Cucliciu, Gita Thapaliya and Gladys O. Latunde-Dada* \\ Diabetes and Nutritional Sciences Division, Faculty of Life Sciences and Medicine, King's College London, Franklin Wilkins \\ Building, 150 Stamford Street, London SE1 9NH, London, UK
}

(Submitted 20 September 2016 - Final revision received 5 January 2017 - Accepted 6 January 2017)

\section{Abstract}

Strategies for preventing Fe deficiency include Fe supplementation and Fe fortification of foods. The absorption, metabolism and chemical characteristics of Fe multi-amino acid chelate (IMAAC) are not known. Absorption of IMAAC was compared with FeSO $\mathrm{S}_{4}$ in Fe-depleted mice and in vitro chemical studies of the Fe supplement was performed in HuTu 80 cells. Hb repletion study was carried out in Fe-deficient CD1 mice that were fed for $10 \mathrm{~d}$ a diet supplemented with ferrous IMAAC or FeSO 4 . A control group of Fe-replete mice was fed a diet with adequate Fe concentrations throughout the study. Tissues were collected from the mice, and the expression of Fe-related genes was determined by quantitative PCR. Ferric reductase and Fe uptake were evaluated in HuTu 80 cells. Supplementation of the diet with FeSO 4 or IMAAC significantly increased Hb levels $(P<0.001$ ) in Fe-deficient mice from initial 93.9 (sD 10.8) or 116.2 (sD 9.1) to 191 (sD 0.7) or 200 (sD 0.5) g/l, respectively. Initial and final $\mathrm{Hb}$ for the Fe-deficient control group were 87.4 (SD 6.7) and 111 (SD 11.7) g/l, respectively. Furthermore, the liver non-haem Fe of both supplement groups increased significantly $(P<0 \cdot 001)$. IMAAC was more effective at restoring Fe in the spleen compared with $\mathrm{FeSO}_{4}(P<0 \cdot 005)$. Gene expression showed the IMAAC supplement absorption is regulated by the body's Fe status as it significantly upregulated hepcidin $(P<0.001)$ and down-regulated duodenal cytochrome b mRNA $(P<0.005)$, similar to the effects seen with FeSO significant proportion of $\mathrm{Fe}$ in IMAAC is reduced by ascorbic acid. Fe absorption in mice and cells was similar for both IMAAC and FeSO 4 and both compounds induce and regulate Fe metabolism genes similarly in the maintenance of homeostasis in mice.

Key words: Bioavailability: Iron: Cells: Mice

Fe deficiency anaemia (IDA) is a nutritional disorder afflicting large population groups in the world ${ }^{(1)}$. It is prevalent amongst vulnerable infants, adolescent girls, pregnant women and the aged in both developed and developing countries. The challenge of increased physiological requirements of Fe for growth and reproduction, within these population groups is compounded by inadequate intake and poor Fe bioavailability from foods ${ }^{(2)}$. This is particularly evident in populations subsisting predominantly on vegetables or plants for their sources of Fe. Substantive evidence has shown that IDA has debilitating effects on cognition, mental function, work performance and pregnancy outcomes ${ }^{(3,4)}$. Consequently, Fe supplementation and fortification of staple foods in different countries ${ }^{(5)}$ have been practical approaches to alleviate this important nutritional disorder. Fe compounds used for such purposes include ferrous sulphate, ferric pyrophosphate, fumarate, gluconate and ferric ammonium citrate among a host of others. Some of these Fe formulations, because they are redox active, cause irritations or disturbances to the gastrointestinal tract by inducing stomach upset, abdominal pain, constipation or nausea ${ }^{(6-8)}$. Fe supplements, as a locus of high concentration of Fe in the gastrointestinal lumen, could cause DNA damage by generating reactive oxygen species in Fenton reaction. Strategies and initiatives aimed at ameliorating some of the adverse effects of Fe supplements led to the synthesis of nano Fe compounds such as a nano particulate ligand modified Fe(III) polyoxohydroxide $^{(9)}$ and nanoparticulate Fe pyrophosphates ${ }^{(7)}$, which were shown to have high bioavailability. This promising outcome underlines the need to exploit and explore other formulations or compounds that exhibit rigid chemical structures, are redox inert, and are highly soluble to maintain colloidal Fe for absorption in the milieu of the gastrointestinal tract. Consequently, Fe multi-amino acid chelate (IMAAC) was formulated and found to be better tolerated than $\mathrm{FeSO}_{4}$ in a randomised, double-blind placebo-controlled trial (RCT) in healthy premenstrual women ${ }^{(10)}$. There is currently no information on the metabolism and the mechanism of Fe absorption from IMAAC. The present study, therefore, investigates the

Abbreviations: DCYTB, duodenal cytochrome b; IDA, Fe deficiency anaemia; Hb, haemoglobin; IMAAC, Fe deficiency anaemia; RPL 19 , ribosomal protein L19.

* Corresponding author: Dr G. O. Latunde-Dada, email: yemisi.latunde-dada@kcl.ac.uk

$\dagger$ Present address: Department of Physiology, Institute of Nutrition and Food Technology 'José Mataix Verdú', University of Granada, Spain. 
bioavailability, characteristics and metabolism of IMAAC using both in vitro cell culture and in vivo mice models. It is hypothesised that Fe absorption from IMAAC will be comparable with that of standard $\mathrm{FeSO}_{4}$. To test this hypothesis, anaemic mice were administered IMAAC or $\mathrm{FeSO}_{4}$ to evaluate $\mathrm{Hb}$ regeneration, serum, liver and spleen Fe levels and Fe-related genes in the tissues.

\section{Methods}

\section{Reagents and chemicals}

Unless otherwise stated chemicals and reagents were obtained from Sigma-Aldrich. Standard American Institute of Nutrition diet (AIN-76A) without Fe (low-Fe diet) and the Fe-replete diet contained $48 \mathrm{mg} / \mathrm{kg}$ Fe were provided to the mice. IMAAC was prepared and supplied by Biotron Laboratories, Centerville UT, USA. IMAAC used contained $10 \%$ elemental Fe chelated in an aqueous solution to low molecular weight peptides, polypeptides and amino acids derived from enzymatically hydrolysed soya protein isolates using non-GM organism Food chemical codex/food grade enzymes. The preparation is then dried and milled to a fine powder. IMAAC preparation with excipients was used in a RCT to test safety and tolerability ${ }^{(10)}$.

\section{Animal studies}

Three-week-old CD1 strain male mice (Charles Rivers) were used for the studies. Mice were housed in a light- and a temperature-controlled room with ad libitum access to diet and water. Fe-deficient diet (TD 80396, 3/kg Fe, and Fe-replete diet TD $80396,48 \mathrm{mg} / \mathrm{kg}$ ferric citrate (Harlan Teklad) were used for the experiment and the diets composition, a modification of AIN-76A is given by Chaudhury et $a l^{(11)}$.

\section{Hb repletion study}

In all, fifteen CD1 mice were made Fe deficient on a low Fe diet of $3 \mathrm{mg} / \mathrm{kg}$, for 3 weeks. Five mice were also placed on a normal Fe-replete diet $(48 \mathrm{mg} / \mathrm{kg})$ to serve as a control. Following this, blood was withdrawn from the tails to determine the initial $\mathrm{Hb}$ levels of the mice. The Fe-depleted mice were then divided into three treatment groups based on similar $\mathrm{Hb}$ levels. These fifteen mice were maintained on the low-Fe diet in groups of five, of which one group did not receive any $\mathrm{Fe}$ supplementation (low-Fe diet), the two other groups were gavaged daily liquid solutions of $150 \mu \mathrm{g}$ of $\mathrm{Fe}$ as IMAAC or $\mathrm{FeSO}_{4}$. This was done for $10 \mathrm{~d}$, and the total food consumption of the mice was measured. After $10 \mathrm{~d}$ of Fe supplementation, the mice were weighed, anaesthetised and blood samples were taken for $\mathrm{Hb}$ and serum $\mathrm{Fe}$ determinations. The mice were then killed, and the spleen, duodenum, kidney and liver samples were excised, snap frozen in liquid $\mathrm{N}_{2}$ and stored in $-80^{\circ} \mathrm{C}$ for further analysis. The experiment was approved by the Institutional (King's College London) Animal Welfare and Ethics Board. All procedures were approved and conducted in accordance with the UK Animals (Scientific Procedures) Act, 1986.
Measurement of $\mathrm{Hb}$, serum iron and tissue non-haem Fe contents

$\mathrm{Hb}$ concentrations were calculated from the change in optical density at $540 \mathrm{~nm}$, following the addition of $5 \mu \mathrm{l}$ of whole blood to Drabkin's reagent (Sigma-Aldrich) and centrifugation (Heraeus Biofuge Pico) at $13000 \mathrm{rpm}$ for $5 \mathrm{~min}$. Serum Fe was measured with a liquid ferrozine-based Fe reagent (Thermo Electron).

Tissue non-haem iron. Tissue samples were weighed and homogenised (1:5, w/v) in $0 \cdot 15 \mathrm{M}-\mathrm{NaCl}$ in $10 \mathrm{~mm}-\mathrm{NaOH}-\mathrm{Hepes}$ buffer ( $\mathrm{pH}$ 7.0) using a $1 \mathrm{ml}$ glass Dounce homogenizer (Wheaton Scientific). An aliquot of the homogenate was then analysed for non-haem Fe content as described by Simpson \& Peters $^{(12)}$. The Fe values were expressed as either content ( $\mu \mathrm{mol}$ $\mathrm{Fe} /$ organ) or concentration (nmol Fe/mg wet weight).

\section{Quantitative real-time reverse transcription $P C R$}

Total RNA was extracted from tissue samples using TRIZOL reagent (Invitrogen) according to manufacturer's instructions. Quantitative RT-PCR was carried out using an ABI Prism 7000 (Applied Biosystems) detection system in a two-step protocol with Roche Universal primers and probes. Quantitative measurement of each gene was normalised to the cycle threshold value for ribosomal protein L (ribosomal protein L19 (RPL 19)).

Sequences of mouse primers used, forward and reverse, respectively, are as follows:

$\begin{array}{ll}\text { Dcytb forward } & \text { GTGACCGGCTTCGTCTTC } \\ \text { Dcytb reverse } & \text { TGGATGGATTTCATCAAGAGC } \\ \text { Hepcidin } \text { forward } & \text { AGAAAGCAGGGCAGACATTG } \\ \text { Hepcidin reverse } & \text { CACTGGGAATTGTTACAGCATT } \\ \text { DMT1 forward } & \text { CACCGTCAGTATCCCAAGGT } \\ \text { DMT1 reverse } & \text { CCAATGATTGCCAACTCCA } \\ \text { Ferroportin forward } & \text { TTGTTGTTGTGGCAGGAGAA } \\ \text { Ferroportin reverse } & \text { AGCTGGTCAATCCTTCTAATGG } \\ \text { RPL } 19 \text { forward } & \text { CTCGTTGCCGGAAAAACA } \\ \text { RPL } 19 \text { reverse } & \text { TCATCCAGGTCACCTTCTCA }\end{array}$

Cell studies

Duodenal HuTu 80 cells were obtained from the American Type Culture Collection. Cells were cultured in Dulbecco's Modified Eagle Medium (DMEM; Life Technologies ${ }^{\text {TM }}$ ) supplemented with $10 \%$ fetal calf serum (Sigma-Aldrich) and with $100 \mathrm{kU} / 1$ of penicillin and $100 \mathrm{mg} / 1$ streptomycin. Cells were maintained at $37^{\circ} \mathrm{C}$ in an atmosphere of $5 \% \mathrm{CO}_{2}$ and $95 \%$ air at a relative humidity of approximately $95 \%$. Cells were passaged at $70 \%$ confluence using Gibco ${ }^{\circledR}$ Versene Solution (Life Technologies $^{\mathrm{TM}}$ ).

Iron uptake. A balanced salt solution (BSS) containing $130 \mathrm{~mm}-$ $\mathrm{NaCl}, 10 \mathrm{~mm}-\mathrm{KCl}, 1 \mathrm{~mm}-\mathrm{MgSO}_{4}, 5 \mathrm{~mm}$-glucose and $1.8 \mathrm{~mm}^{-\mathrm{CaCl}_{2}}$ in $10 \mathrm{~mm}$-piperazine- $N, N^{\prime}$-bis(2-ethanesulfonic acid) buffer ( $\mathrm{pH}$ 6.5) that was reported to prevent precipitation or aggregation of 
nano-Fe(III), Fe compound was used for cell uptake studies ${ }^{(13)}$. Unless otherwise stated the Fe concentration was $10 \mu \mathrm{m}$. Confluent HuTu 80 cells were exposed to serum-free DMEM for $4 \mathrm{~h}$ before Fe uptake studies. The cells were washed with prewarmed PBS before incubation with the different Fe compounds or the non-supplemented BSS control for $1 \mathrm{~h}$ at $37^{\circ} \mathrm{C}$. After the Fe incubation period, the uptake medium was decanted, and cells were washed three times with PBS-EDTA ( $2 \mathrm{~mm}$ ) to remove Fe that bound non-specifically to the cell membrane. Cells were suspended in fresh serum-free DMEM and incubated for a further $23 \mathrm{~h}$ for ferritin synthesis. Following this incubation period, cells were washed with PBS and lysed with Mammalian Protein Extraction Reagent (Thermo Fisher Scientific). The cell lysate was centrifuged $(5 \mathrm{~min}, 16000 \mathrm{~g})$ to remove cell debris and the supernatant used for ferritin and protein analysis.

Ferritin ELISA assay in cell lysates. The Spectro Ferritin MT ELISA Kit (ATI Atlas) was used to determine cellular ferritin content as described in the manufacturer's protocol. Cellular protein concentration was determined according to Bio-Rad assay protocol (Bio-Rad Laboratories). Experiments were carried out in triplicates, and data are expressed as ng ferritin per mg protein.

Fe uptake and the effect of ferrous $\mathrm{Fe}$ inhibition were determined in cells by co-incubating ferrozine $(1 \mathrm{mM})$ with $20 \mu \mathrm{M}$ Fe from IMAAC and $\mathrm{FeSO}_{4}$ for $1 \mathrm{~h}$. Following this, cells were washed with versene (PBS-EDTA solution) and incubated with serum-free DMEM for $23 \mathrm{~h}$ to allow ferritin synthesis.

\section{Ferric reductase assay}

Ferric reductase assay was performed on HuTu 80 cells plated into twelve well plates. The cells were washed three times with PBS, before incubation in a BSS buffer supplemented with either IMAAC or ferric citrate (different concentrations) and $200 \mu \mathrm{M}$ 3-(2-pyridyl)-5,6-diphenyl 1,2,4-triazine - 40 400-disulfonic acid sodium salt (ferrozine). Ferric reduction of Fe was measured by the formation of the coloured Fe(II)-ferrozine complex and monitoring the change in absorbance at $562 \mathrm{~nm}$.

\section{Statistical analysis}

All values are expressed as means with their standard errors from at least three different experiments. Statistical differences between means were calculated using Student's $t$ test in correcting for differences in sample variance. When multiple comparisons were necessary, one-way or two-way ANOVA was performed, using GraphPad with Tukey's post hoc test. Differences were considered significant at $P<0.05$.

\section{Results}

In vivo bioavailability of Fe multi-amino acid chelate in a mouse feeding study

There were no statistical differences $(P>0.05)$ in initial and final body weights between the experimental groups over the intervention period (Table 1). Average feed intake was $71.76 \mathrm{~g}$ and there were no differences between the groups (Table 1). $\mathrm{Fe}$ intakes of mice expressed as $\mathrm{mg} / \mathrm{kg}$ body weight are, respectively, 0.62 (SD 0.02), 4.27 (SD 0.11), 4.54 (SD 0.17) and 9.88 (SD 0.33) for Fe-deficient, FeSO4, IMAAC and Fe-replete diets.

Efficacy of $\mathrm{Hb}$ repletion was employed to compare IMAAC and FeSO4 following diet-induced Fe deficiency. Mice fed a diet low in Fe (Fe-deficient group) for 4 weeks showed significantly $(P<0 \cdot 001)$ lower blood $\mathrm{Hb}$ levels than control mice kept on the Fe-replete diet (Fe-replete group) throughout (Fig. 1(a)). Supplementation of the Fe-deficient diet with either IMAAC or $\mathrm{FeSO}_{4}$ for $10-\mathrm{d}$ significantly increased $\mathrm{Hb}$ levels in comparison with mice fed the Fe-deficient diet throughout $(P<0.001$ and $P<0.005$ ), respectively (Fig. 1(a)). Furthermore, Fig. 1(b) shows that only supplemented mice had a significant gain in $\mathrm{Hb}$ levels from baseline. Moreover, serum Fe levels were significantly higher in the mice fed the Fe-replete diet $(P<0.005)$ or supplemented Fe $(P<0.001)$ than the mice on the Fe deficient diet (Fig. 1(c)). There was no significant difference in serum Fe between mice, which were given $\mathrm{FeSO}_{4}$ or IMAAC supplementation $(P>0 \cdot 05)$.

\section{Tissue non-haem iron of mice}

Mice receiving Fe supplementation had significantly higher liver non-haem Fe levels (Fig. 2(a)) than the mice receiving the Fe-replete diet $(P<0 \cdot 005)$ and the Fe-deficient diet $(P<0 \cdot 001)$. Mice on the control Fe-replete diet had significantly higher liver Fe levels that the Fe-deficient group $(P<0.05)$ as expected. There was no difference in liver levels of Fe between $\mathrm{FeSO}_{4}$ and IMAAC supplementation $(P>0 \cdot 05)$. Similarly, mice on $\mathrm{Fe}$ replete or $\mathrm{FeSO}_{4}$ or IMAAC supplementation exhibited significantly higher $(P<0.001)$ splenic Fe levels than mice fed

Table 1. Initial and final body weights and feed intake of the experimental groups*

(Mean values and standard deviations, $n 5$ )

\begin{tabular}{|c|c|c|c|c|c|c|c|c|}
\hline \multirow[b]{2}{*}{ Groups } & \multicolumn{2}{|c|}{ Fe-replete } & \multicolumn{2}{|c|}{ Fe-deficient } & \multicolumn{2}{|c|}{$\mathrm{FeSO}_{4}$} & \multicolumn{2}{|c|}{ IMAAC } \\
\hline & Mean & $\mathrm{SD}$ & Mean & SD & Mean & $\mathrm{SD}$ & Mean & SD \\
\hline Initial body weight (g) & 34.04 & 1.9 & $32 \cdot 17$ & $2 \cdot 4$ & 34.19 & $2 \cdot 3$ & $32 \cdot 60$ & $2 \cdot 8$ \\
\hline Final body weight (g) & 34.85 & $2 \cdot 7$ & 33.74 & 1.9 & $35 \cdot 24$ & $2 \cdot 0$ & 33.27 & $3 \cdot 0$ \\
\hline Feed intake $(\mathrm{g}) / 10 \mathrm{~d}$ & 71.38 & 0.8 & 71.43 & 1.5 & 72.45 & 1.6 & 71.78 & 0.9 \\
\hline
\end{tabular}

IMAAC, Fe multi-amino acid chelate.

* Data were analysed by two-way ANOVA followed by the Tukey's post hoc test. There were no significant differences in the parameters between the groups. 
(a)

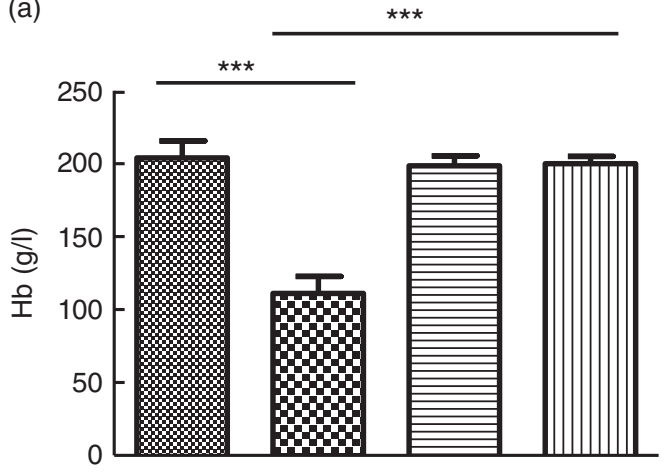

(b)

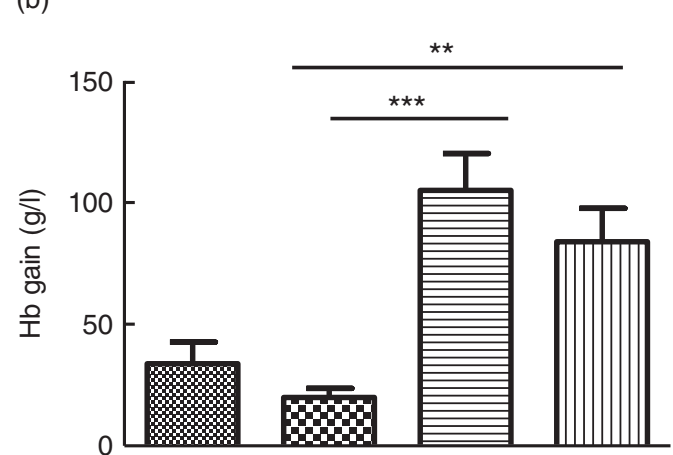

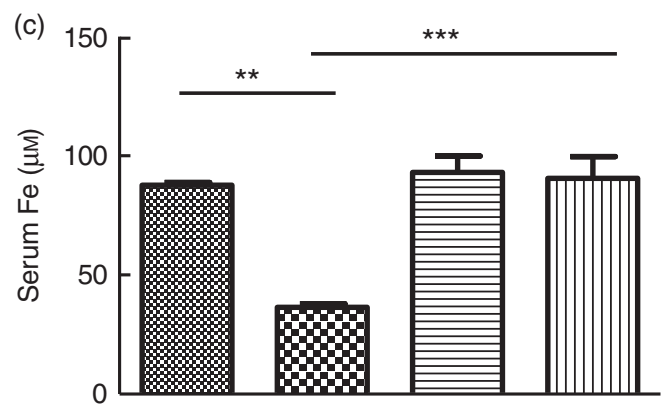

Fig. 1. Intragastric administration of iron multi-amino acid chelate (IMAAC) or $\mathrm{FeSO}_{4}$ and haematic responses of anaemic mice. $\mathrm{Hb}$ levels of male CD1 mice following 10-d of administering the test diets (a), Hb gains (b) and serum iron levels in the mice (c). Iron-replete (圈) control diet contained $48 \mathrm{mg} \mathrm{Fe} / \mathrm{kg}$ diet; the iron-deficient (图) diet contained approximately $3 \mathrm{mg} \mathrm{Fe} / \mathrm{kg}$ diet. Mice were maintained on the iron-deficient diet and were supplemented daily by oral gavage with $150 \mu \mathrm{Fg}$ as IMAAC (四) or $\mathrm{FeSO}_{4}$ (目). Values are means $(n 5)$, with their standard errors. ${ }^{\star} P<0.05,{ }^{\star \star} P<0.01,{ }^{\star \star \star} P<0.001$.

(a)
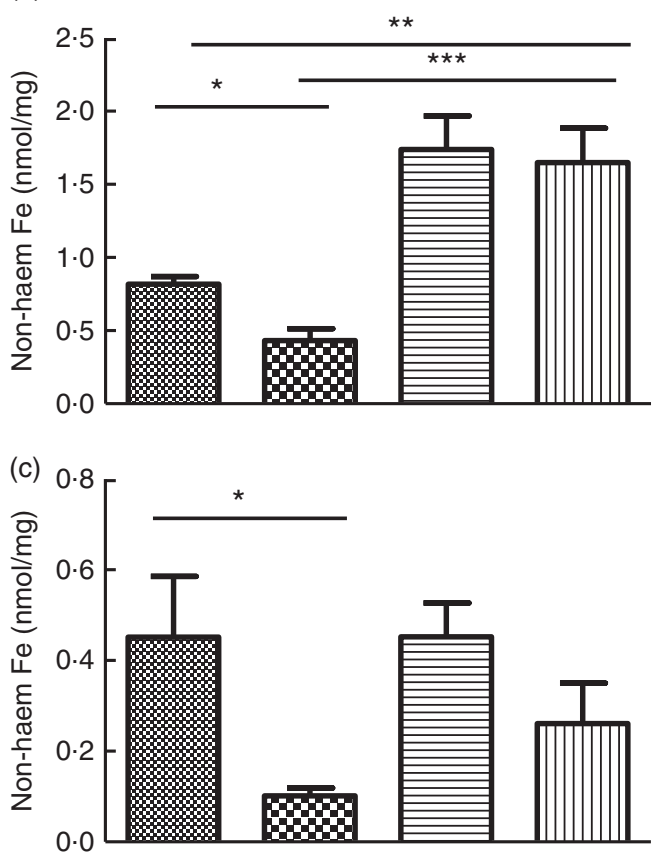

(b)

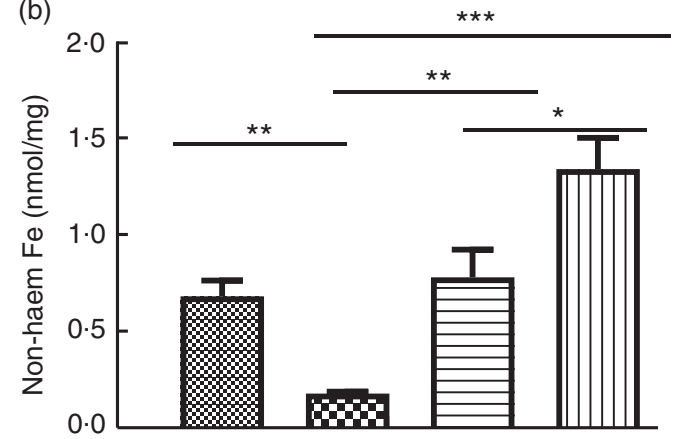

(d)

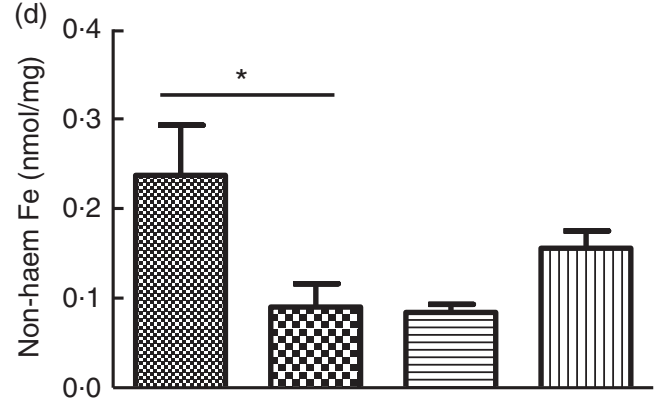

Fig. 2. Intragastric administration of iron multi-amino acid chelate (IMAAC) or $\mathrm{FeSO}_{4}$ and tissue iron distribution of anaemic mice. Non-haem iron levels in the liver (a), spleen (b) duodenum (c) and kidney (d) of male CD1 mice following 10-d feeding with different test diets. Iron-replete (圈) control diet contained $48 \mathrm{mg}$ Fe/ $\mathrm{kg}$ diet; the iron-deficient (圈) diet contained approximately $3 \mathrm{mg} \mathrm{Fe} / \mathrm{kg}$ diet. Mice were maintained on the Fe-deficient diet and were supplemented daily by oral gavage with $150 \mu \mathrm{g}$ Fe as IMAAC (四) or $\mathrm{FeSO}_{4}$ (目). Values are means $(n 5)$, with their standard errors. ${ }^{\star} P<0.05,{ }^{\star \star} P<0.01,{ }^{\star \star \star} P<0.001$.

Fe-deficient diet (Fig. 2(b)). As shown in Fig. 2(c), although the duodenal $\mathrm{Fe}$ levels increased in mice fed $\mathrm{FeSO}_{4}$ or IMAAC supplements, the difference only reached significance level
$(P<0.05)$ in the mice on the replete Fe diet compared with mice on the Fe-deficient diet. This trend is similar to the observation in the kidney as shown in Fig. 2(d). 
(a)

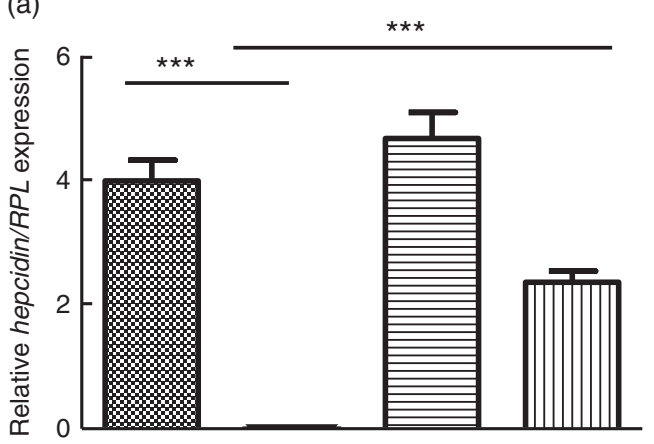

(c)

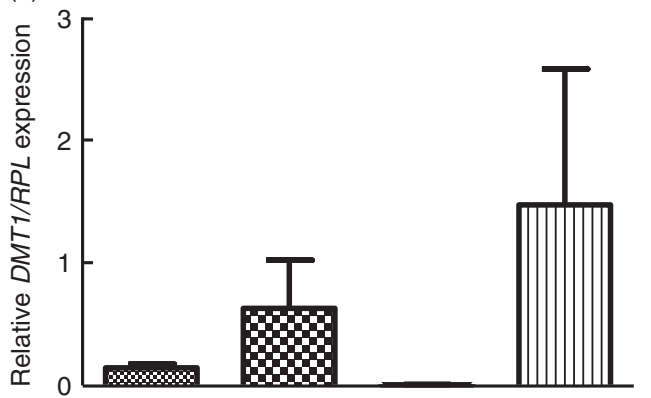

(b)

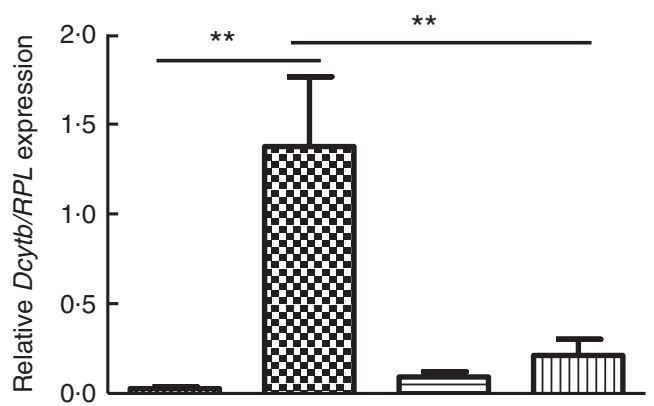

(d)

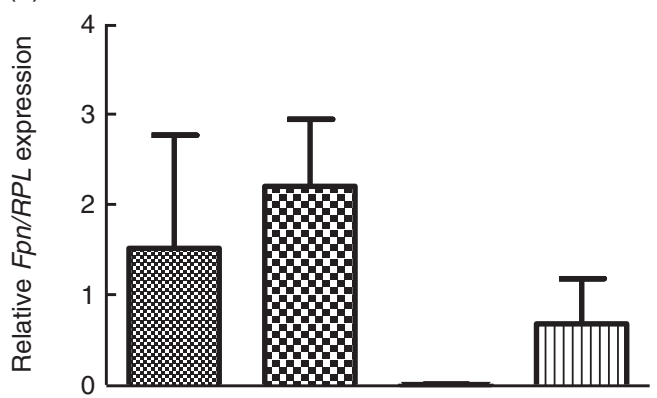

Fig. 3. Intragastric administration of iron multi-amino acid chelate (IMAAC) or $\mathrm{FeSO}_{4}$ and $\mathrm{mRNA}$ levels of iron metabolism genes of anaemic mice. Hepcidin mRNA levels in the liver (a) of male CD1 mice following 10-d feeding with different test diets as described above. Dcytb mRNA expression (b), DMT1 (c) and ferroportin (Fpn) (d) levels in the duodenum of mice on experimental diets. 图, iron replete; 圈, iron deficient; 目, $\mathrm{FeSO}_{4}$; 四, IMAAC. ${ }^{*} P<0.05,{ }^{* \star} P<0.01,{ }^{* \star *} P<0.001$.

\section{Gene expression in the duodenum and liver tissues of mice}

As expected Fig. 3(a) indicates that bepcidin mRNA expression in the liver was up-regulated significantly in animals fed Fe replete and supplemented Fe and significantly down-regulated in animals on the Fe-deficient diet $(P<0 \cdot 001)$. Consequently, duodenal cytochrome b (Dcytb) mRNA levels (Fig. 3(b)) increased in the duodenum of the mice were given the Fe-deficient diet. Moreover, a trend of increase was observed in the duodenal levels of divalent metal transporter 1 (DMT1) and Fpn mRNA of Fe-deficient mice (Fig. 3(c) and (d)). Fe supplementation, however, significantly $(P<0 \cdot 01)$ down-regulated $D c y t b$ mRNA levels in the duodenum of mice. Down-regulation of $\mathrm{Fe}$ transport genes was more responsive to $\mathrm{FeSO}_{4}$ than IMAAC administration (Fig. 3(c) and (d)).

\section{In vivo iron uptake and ferric iron reduction studies in $\mathrm{HuTu}$ $80 \mathrm{cells}$}

Consistent with the observation in the in vivo mouse studies, IMAAC and $\mathrm{FeSO}_{4}$ exhibited comparable $\mathrm{Fe}$ uptake values in HuTu 80 cells (Fig. 4(a)). However, Fe(II) chelator ferrozine, significantly inhibited $\mathrm{Fe}$ uptake and utilisation from $\mathrm{FeSO}_{4}$ $(P<0 \cdot 05)$, the effect on IMAAC was not significant (Fig. 4(b)). Ferric citrate reduction in HuTu 80 cells exhibited $\mathrm{pH}$ dependent activity that is higher than that of IMAAC (Fig. 4(c) and (d)). Reductase activity was significantly different $(P<0.001)$ between $\mathrm{pH} 3.5$ and 7.4 for both ferric citrate and IMAAC. However, reduction of $\mathrm{Fe}$ and dissolution in the presence of ascorbic acid was higher with IMAAC (Fig. 4(c) and (d)). Ascorbic acid significantly enhanced $(P<0 \cdot 01)$ ferric reduction in both $\mathrm{Fe}$ compounds.

\section{Discussion}

Fe supplementation and food fortification are panaceas aimed at improving Fe nutrition ${ }^{(14,15)}$ particularly to the vulnerable groups of the population. These strategies, however, are associated with diverse issues limiting effectiveness and as such are subjects of continuing research and investigations. $\mathrm{FeSO}_{4}$, the standard Fe supplement is highly reactive, potentially toxic and prone to causing gastrointestinal disturbances. Alternatives such as IMAAC was reported to be better tolerated than $\mathrm{FeSO}_{4}$ in a RCT in healthy premenstrual women ${ }^{(10)}$. The bioavailability, metabolism and the mechanism of Fe absorption from IMAAC were consequently investigated in Fe-deficient mice in the present study. In general, studies in humans revealed that differences in diets that vary in bioavailability are apparent in Fe-deficient rather than in Fe-replete subjects ${ }^{(16)}$.

The data demonstrate the comparable efficiency of both IMAAC and ferrous sulphate in replenishing $\mathrm{Hb}$ in Fe-deficient mice and similar Fe uptake in vitro in intestinal HuTu 80 cells. This agrees with the observation of which Fe glycine chelate compared with $\mathrm{FeSO}_{4}$ in $\mathrm{Hb}$ repletion of chicks ${ }^{(17)}$ and in a study that examines ferrous carbamoyl glycine with $\mathrm{FeSO}_{4}$ in rats ${ }^{(18)}$. Furthermore, Fe glycine chelate was equally efficacious in treating cancer patients with mild IDA ${ }^{(19)}$. Remarkably, however, IMAAC is a repository of Fe and several amino acids. Consequently, tolerability of IMAAC possibly accrues from combined antioxidant properties of the constituent multiple amino $\operatorname{acids}^{(20)}$. 
(a)
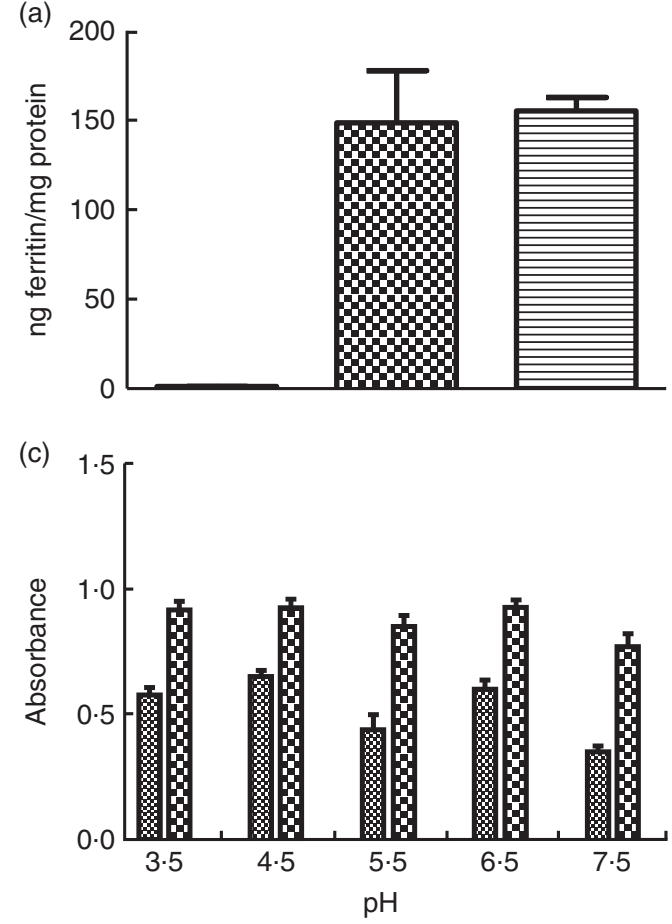

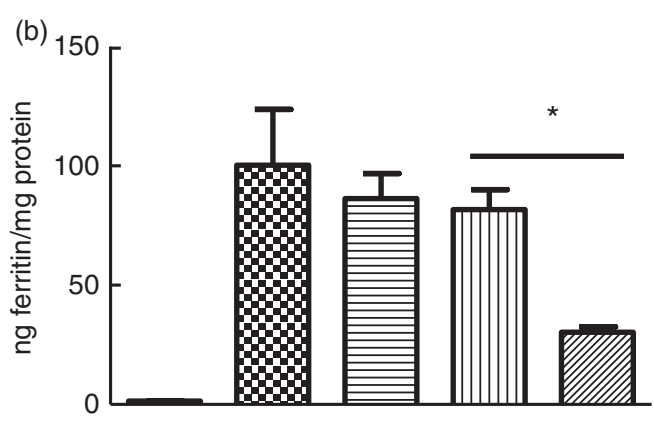

(d)

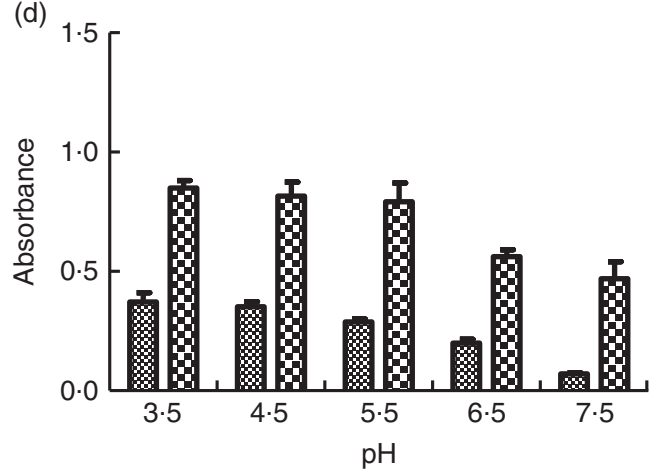

Fig. 4. Iron uptake and in vitro solubilisation of iron multi-amino acid chelate (IMAAC) in HuTu 80 cells. Cellular ferritin levels in HuTu 80 cells (a) after a 1-h exposure to $50 \mu \mathrm{m}(\mathrm{Fe})$ as IMAAC, ferrous sulphate $\left(\mathrm{FeSO}_{4}\right)$ or co-incubation with ferrozine $(1 \mathrm{~mm})(\mathrm{b})$. Effect of varying $\mathrm{pH}$ and on reductive iron dissolution from IMAAC (c) or ferric citrate (d). HuTu 80 cells were exposed to $50 \mu \mathrm{m}(\mathrm{Fe})$ as IMAAC, $\mathrm{FeSO}_{4}$ in balanced salt solution following which (Fe(II) was measured using ferrozine. Total reducible iron was subsequently determined by the addition of ascorbic acid $(1 \mathrm{~mm})$. Values are means, and standard deviations of three independent experiments with three replicate wells per experiment. 圆, Untreated cells; 图, IMAAC; 目, IMAAC + ferrozine; 四, $\mathrm{FeSO}_{4}$; 四, FeSO ${ }_{4}$ + ferrozine; 圈, IMAAC; 图, IMAAC + ascorbic acid; 음, ferric citrate; : ferric citrate + ascorbic acid.

The study next compared the metabolism of Fe in IMAAC with $\mathrm{FeSO}_{4}$ in mice. During Fe deficiency, liver and spleen Fe stores are rapidly depleted to maintain Fe homoeostasis and functional $\mathrm{Fe}$ requirements. Consequently, repletion of these tissues during $\mathrm{Fe}$ supplementation is a relative marker of bioavailability. IMAAC and $\mathrm{FeSO}_{4}$ supplementation had equivalent levels of liver Fe repletion (Fig. 2(a)) compared with the Fe-deficient diet $(P<0 \cdot 001)$. Furthermore, in the spleen (Fig. 2(b)) the level of non-haem Fe was higher in the mice given IMAAC $(P<0.005)$ than $\mathrm{FeSO}_{4}$ compared with the Fe-deficient diet. In fact, $\mathrm{FeSO}_{4}$ caused a similar level of splenic non-haem Fe to the Fe-replete diet. The spleen is the last tissue in the body to replenish its Fe stores after Fe deficiency ${ }^{(21)}$. This observation was also evident in pregnant pigs that were given hydrolysed soya protein Fe AAC supplement for 4 weeks before parturition. On analysis, there was $34.5 \%$ greater non-haem Fe levels in the liver and $8.5 \%$ higher Fe in the spleen of piglets whose mothers were given the Fe amino acid chelate supplement compared with the control group ${ }^{(22)}$. In addition to tissue Fe, IMAAC modulation of Fe metabolism genes in mice was also evident in the present study.

Remarkably, though, administration of IMAAC supplement for $10 \mathrm{~d}$ replenished Fe stores of anaemic mice to the same level as the normal healthy mice kept on the Fe replete diet despite significant difference $(P<0.001)$ in Fe intake $(4.54$ (SD 0.17) v. 9.88 (SD 0.33$) \mathrm{mg} / \mathrm{kg}$ body weight). Fe intake $(4.27$ (SD 0.11$) \mathrm{mg} / \mathrm{kg}$ body weight) of mice that were given $\mathrm{FeSO}_{4}$ was comparable with those on IMAAC. This attests to the superior Fe bioavailability of IMAAC and $\mathrm{FeSO}_{4}$ than ferric citrate Fe component of the Fe-replete diet (TD 80396, 48 mg/kg ferric citrate (Harlan Teklad). Contrary to some concerns ${ }^{(23)}$ that Fe chelates if absorbed intact could bypass the normal homoeostatic regulatory mechanisms, Fe amino acid chelates were reported to be regulated by the body's Fe status in humans ${ }^{(24)}$. Expression of hepcidin and other Fe metabolism genes were mostly appropriately modulated by IMAAC and $\mathrm{FeSO}_{4}$ supplementation in the present study. As expected from gene expression studies, hepcidin mRNA levels (Fig. 3(a)) was down-regulated in mice given the Fe-deficient diet and up-regulated by both Fe supplements $(P<0.005)$. Consequently, DMT1, ferroportin and, in particular, Dcytb mRNA levels (Fig. 3(b)-(d)) were up-regulated in mice on the Fe-deficient diet and down-regulated in both groups on supplements $(P<0 \cdot 001)$. These results reflect the effectiveness of both Fe supplements in resolving IDA. Furthermore, increased hepcidin expression will exert a negative feedback regulation of the genes involved in Fe transport machinery until Fe homoeostasis is restored. $\mathrm{Hb}$ repletion and hepatic hepcidin mRNA levels exhibited a trend that reflected responsiveness to bioavailability of IMAAC and $\mathrm{FeSO}_{4}$ in mice (Figs. 1(a) and 3(a)). This might be similar to the luminal endocytic uptake of nanoparticulate $\mathrm{Fe}^{(3+)}$ poly oxo-hydroxide (nanoFe ${ }^{(3+)}$ ), which differs from the uptake mechanism of inorganic ferrous ion ${ }^{(9)}$, but both share a ferroportin-dependent abluminal efflux mechanism into the circulation $^{(25)}$. This is consistent with the concept of the labile Fe 
pool $^{(26)}$ in the cytosol, where $\mathrm{Fe}$ is released from inorganic or organic complexes into the common matrix for efflux into circulation as regulated by ferroportin/hepcidin interaction.

The chemical nature of IMAAC and the mechanism of the Fe uptake process were studied in duodenal HuTu 80 cells (Fig. 4(a)). The data suggest that the content of ferrous chelatable $\mathrm{Fe}$ is more negligible in IMAAC than $\mathrm{FeSO}_{4}$ (Fig. 4 (b)). Food Fe sources and Fe salts are liable to autoxidation to the ferric form as they traverse the neutral $\mathrm{pH}$ section of the gastrointestinal tract. Consequently, the rate of dissolution of $\mathrm{Fe}$ in different formulations ${ }^{(27)}$ is critical in the absorption efficiency. We next investigated the reductive dissolution of IMAAC in the presence of ascorbic acid and compared this to ferric citrate. While ferric citrate exhibited a $\mathrm{pH}$-dependent reductive dissolution of $\mathrm{Fe}$ (Fig. 4(c) and (d)), the dissolution of IMAAC seems independent of $\mathrm{pH}$. Ferrozine chelable Fe was higher for $\mathrm{FeSO}_{4}$ than that of IMAAC, thus implying the availability of less redox active species in the later. This perhaps explains the reported higher tolerability of IMAAC over $\mathrm{FeSO}_{4}$ in a RCT in human subjects ${ }^{(10)}$. However, negligible free ferric Fe component of IMAAC could be easily reduced by ascorbic acid (Fig. 4(c)). Chelation, sequestration and encapsulation of Fe by amino acids and peptides possibly prevent redox reactivity in the lumen of the gastrointestinal tract. For inorganic Fe salts, however, the rate of autoxidation and dissolution of the ferric $\mathrm{Fe}$ in different formulations ${ }^{(27)}$ could be critical in the absorption efficiency in the proximal duodenal tract. However, the resultant consequences on microbial population and the generation of reactive $\mathrm{Fe}$ species in the distal duodenum are subject of continuing investigation ${ }^{(28)}$.

IMAAC has been shown to compare favourably well with $\mathrm{FeSO}_{4}$ in $\mathrm{Hb}$ regeneration of anaemic mice and in vitro HuTu 80 intestinal Fe uptake studies. It has potential, therefore, to be used widely as an alternative to $\mathrm{FeSO}_{4}$ in the management of IDA as it has been shown to be better tolerated than $\mathrm{FeSO}_{4}$ in humans. In vitro cell culture studies offer opportunities for screening Fe compounds such as pyrophosphate, gluconate, ammonium citrate and bis glycinate, etc. as the relative stability of various Fe compounds in vivo has been a matter of uncertainty to the nutrition industry. On the other hand, animal studies may be useful for evaluating relative bioavailability and understanding the mechanisms of Fe absorption; the results may not wholly translate to what occurs in humans and interpretations as such should be treated with caution ${ }^{(29)}$. Future studies on IMAAC could be for a longer duration to investigate the balance of the highly bioavailable Fe species and the potentials of pathogenic microbes to pilfer this Fe source for proliferation in the lower segment of the gastrointestinal tract. Fe absorption in mice and cells was comparable for both IMAAC and $\mathrm{FeSO}_{4}$ and both compounds induced and regulated Fe metabolism genes in a similar way.

\section{Acknowledgements}

G. O. L.-D. acknowledges funding support of the Diabetes and Nutritional Sciences Division, King's College London. The IMAAC supplement called FerriActiv was prepared by Biotron
Laboratories, Centerville, USA. The authors are grateful to Dr Gameil Fouad for providing IMAAC supplement.

G. O. L -D. designed and conducted the research, analysed the data and wrote the manuscript; N. K., C. B., A. C. and G. T. performed the experiments, data collection and statistical analysis.

All authors declare that they have no conflicts of interest.

\section{References}

1. World Health Organization (2014) Micronutrient deficiencies iron deficiency anaemia. http://www.who.int/nutrition/ topics/ida/en/\# (accessed November 2014)

2. Aspuru K, Villa C, Bermejo F, et al. (2011) Optimal management of iron deficiency anemia due to poor dietary intake. Int J Gen Med 4, 741-750.

3. Munoz P \& Humeres A (2012) Iron deficiency on neuronal function. Biometals 25, 825-835.

4. Rufer ES, Tran TD, Attridge MM, et al. (2012) Adequacy of maternal iron status protects against behavioral, neuroanatomical, and growth deficits in fetal alcohol spectrum disorders. PLOS ONE 7, e47499.

5. Gera T, Sachdev HS \& Boy E (2012) Effect of iron-fortified foods on hematologic and biological outcomes: systematic review of randomized controlled trials. Am J Clin Nutr 96 , 309-324.

6. Tiwari AK, Mahdi AA, Chandyan S, et al. (2011) Oral iron supplementation leads to oxidative imbalance in anemic women: a prospective study. Clin Nutr 30, 188-193.

7. Hilty FM, Arnold M, Hilbe M, et al. (2010) Iron from nanocompounds containing iron and zinc is highly bioavailable in rats without tissue accumulation. Nat Nanotechnol $\mathbf{5}$, 374-380.

8. Tolkien Z, Stecher L, Mander AP, et al. (2015) Ferrous sulfate supplementation causes significant gastrointestinal side-effects in adults: a systematic review and meta-analysis. PLOS ONE 10, e0117383.

9. Pereira DI, Bruggraber SF, Faria N, et al. (2014) Nanoparticulate iron(III) oxo-hydroxide delivers safe iron that is well absorbed and utilised in humans. Nanomedicine $\mathbf{1 0}$, 1877-1886

10. Fouad GT, Evans M, Sharma P, et al. (2013) A randomized, double-blind clinical study on the safety and tolerability of an iron multi-amino acid chelate preparation in premenopausal women. J Diet Suppl 10, 17-28.

11. Chaudhury C, Kim J, Mehnaz S, et al. (2006) Accelerated transferrin degradation in HFE-deficient mice is associated with increased transferrin saturation. J Nutr 136, 2993-2998.

12. Simpson RJ \& Peters TJ (1990) Forms of soluble iron in mouse stomach and duodenal lumen: significance for mucosal uptake. Br J Nutr 63, 79-89.

13. Pereira DI, Mergler BI, Faria N, et al. (2013) Caco-2 cell acquisition of dietary iron(III) invokes a nanoparticulate endocytic pathway. PLOS ONE 8, e81250.

14. Prentice AM, Mendoza YA, Pereira D, et al. (2017) Dietary strategies for improving iron status: balancing safety and efficacy. Nutr Rev 75, 49-60.

15. Latunde-Dada GO, Pereira DI, Tempest B, et al. (2014) A nanoparticulate ferritin-core mimetic is well taken up by HuTu 80 duodenal cells and its absorption in mice is regulated by body iron. J Nutr 144, 1896-1902.

16. Hulten L, Gramatkovski E, Gleerup A, et al. (1995) Iron absorption from the whole diet. Relation to meal composition, iron requirements and iron stores. Eur J Clin Nutr 49, 794-808. 
17. Ma WQ, Sun H, Zhou Y, et al. (2012) Effects of iron glycine chelate on growth, tissue mineral concentrations, fecal mineral excretion, and liver antioxidant enzyme activities in broilers. Biol Trace Elem Res 149, 204-211.

18. Zhang Y, Sun X, Xie C, et al. (2015) Effects of ferrous carbamoyl glycine on iron state and absorption in an iron-deficient rat model. Genes Nutr 10, 54 .

19. Ferrari P, Nicolini A, Manca ML, et al. (2012) Treatment of mild non-chemotherapy-induced iron deficiency anemia in cancer patients: comparison between oral ferrous bisglycinate chelate and ferrous sulfate. Biomed Pharmacother 66, 414-418.

20. Elias RJ, Bridgewater JD, Vachet RW, et al. (2006) Antioxidant mechanisms of enzymatic hydrolysates of beta-lactoglobulin in food lipid dispersions. J Agric Food Chem 54, 9565-9572.

21. Chua-anusorn W, Webb J, Macey DJ, et al. (1999) The effect of prolonged iron loading on the chemical form of iron oxide deposits in rat liver and spleen. Biochim Biophys Acta 1454, 191-200.

22. Brady PS, Ku PK, Ullrey DE, et al. (1978) Evaluation of an amino acid-iron chelate hematinic for the baby pig. J Anim Sci 47, 1135-1140.
23. Allen LH (2002) Advantages and limitations of iron amino acid chelates as iron fortificants. Nutr Rev $\mathbf{6 0}$, S18-S21.

24. Olivares M, Pizarro F, Pineda O, et al. (1997) Milk inhibits and ascorbic acid favors ferrous bis-glycine chelate bioavailability in humans. J Nutr 127, 1407-1411.

25. Aslam MF, Frazer DM, Faria N, et al. (2014) Ferroportin mediates the intestinal absorption of iron from a nanoparticulate ferritin core mimetic in mice. FASEB $J \mathbf{2 8}$, 3671-3678

26. Jacobs A (1977) Low molecular weight intracellular iron transport compounds. Blood 50, 433-439.

27. Harju E (1989) Clinical pharmacokinetics of iron preparations. Clin Pharmacokinet 17, 69-89.

28. Pereira DI, Aslam MF, Frazer DM, et al. (2015) Dietary iron depletion at weaning imprints low microbiome diversity and this is not recovered with oral Nano Fe(III). Microbiologyopen 4, 12-27.

29. Reddy MB \& Cook JD (1991) Assessment of dietary determinants of nonheme-iron absorption in humans and rats. Am J Clin Nutr 54, 723-728. 